\title{
Differentiating Dissociative Disorders from Other Diagnostic Groups Through Somatoform Dissociation in Turkey
}

\author{
Vedat Sar, MD \\ Turgut Kundakci, MD \\ Emre Kiziltan, MD \\ Bahadir Bakim, MD \\ Oya Bozkurt, MD
}

\begin{abstract}
This study aimed to assess the reliability, validity, and psychometric characteristics of the Turkish version of the Somatoform Dissociation Questionnaire (SDQ-20). In this context, it investigated whether somatoform dissociation differentiates dissociative disorders from other diagnostic groups and non-clinical individuals. The Turkish Version of the SDQ-20 was administered to 50 patients with a dissociative disorder, 94 patients with psychiatric disorders other than dissociative disorder, and 175 non-clinical participants. To confirm the clinical diagnosis, all patients in the dissociative disorder group had been evaluated using the Structured Clinical Interview for DSM-IV Dissociative
\end{abstract}

Vedat Sar is Professor of Psychiatry, and Director, Clinical Psychotherapy Unit and Dissociative Disorders Program, Department of Psychiatry, Istanbul University.

Turgut Kundakci is Psychiatrist, Student Health Center, Istanbul University.

Emre Kiziltan is Psychiatrist and Doctoral Candidate, Department of Pharmacology, Istanbul Medical Faculty, Istanbul University.

Bahadir Bakim is Psychiatrist, Istinye State Hospital, Istanbul.

Oya Bozkurt is Resident, Department of Psychiatry, Istanbul Medical Faculty, Istanbul University.

Address correspondence to: Prof. Dr. Vedat Sar, Clinical Psychotherapy Unit and Dissociative Disorders Program, Department of Psychiatry, Istanbul University, Istanbul Medical Faculty, Istanbul, 34390 Turkey (E-mail: vsar@istanbul.edu.tr).

Journal of Trauma \& Dissociation, Vol. 1(4) 2000

(c) 2000 by The Haworth Press, Inc. All rights reserved. 
Disorders. The internal consistency and the test-retest correlation of the SDQ-20 were excellent. The scale had strong correlations with the DES and the DIS-Q. There was a statistically significant difference between dissociative patients and other diagnostic groups on the SDQ-20 total score. The discriminative power of the SDQ-20 was as robust as that of the DES. There was no significant difference between the mean SDQ-20 total scores of Turkish and Dutch patients, but Turkish dissociative patients reported pseudoseizures more frequently than Dutch patients. The specificity of the short version of the scale (SDQ-5) was weak among Turkish patients. Dissociative disorders can be differentiated from other diagnostic groups through somatoform dissociation. The good psychometric characteristics of the SDQ-20 among Turkish participants support its cross-cultural validity. [Article copies available for a fee from The Haworth Document Delivery Service: 1-800-342-9678. E-mail address: <getinfo@haworthpressinc.com>Website: <http://www.HaworthPress. com> () 2000 by The Haworth Press, Inc. All rights reserved.]

KEYWORDS. Pseudoseizure, somatization, dissociation, culture, hysteria

Somatoform symptoms are a prominent feature of a group of disorders that involve physical complaints or symptoms that cannot be explained by any underlying organic etiology. Somatization disorder, hypochondriasis, and conversion disorder belong to this group (American Psychiatric Association, 1994). Somatoform symptoms can also be part of various psychiatric disorders such as dissociative disorders, depression, schizophrenic disorder, and anxiety disorders.

In DSM-II (American Psychiatric Association, 1968), following traditional conceptualization, the conversion and dissociative types of hysterical neurosis were classified as variants of a single disorder. In the DSM-III (American Psychiatric Association, 1980), and its subsequent versions, dissociative disorders have been considered a separate group. The latest version of the International Classification of Diseases, the ICD-10 (World Health Organization, 1992), however, includes all manifestations of hysterical neurosis under the rubric of dissociative disorders in accordance with the findings of modern studies that have resurrected evidence for the relationship between somatoform symptoms and dissociation (e.g., Saxe et al., 1994).

Pierre Janet described somatoform symptoms as aspects of hysteria (dissociative disorders) in his traumatized patients (Nijenhuis \& Van der Hart, 1999). In the beginning of his career, his contemporary Sigmund Freud (1895/1974) also considered hysteria as a trauma-based disorder. However, Freud later conceptualized the somatoform symptoms of hysteria as the result of a neurotic defense mechanism and referred to them as conversion symp- 
toms. In his lifelong career aimed at establishing a scientific medical psychology based both on biological and psychological factors, Ernst Kretschmer $(1944,1975)$ pointed out the biological aspects of hysteria and noted the similarity between somatoform reaction types seen among humans and animals. He mentioned the "movement storm" (Bewegungssturm), and "playing dead reflex" (Totstellreflex), which are seen among animals when threatened with death. He saw the symptoms of hysteria as phenomena that any person could develop under certain circumstances.

After the 1950s, while developing a strictly medical model of psychiatric disorders, the earlier work by Briquet was reintroduced (Guze, 1975), and hysteria was redefined as a chronic disorder with multiple somatic complaints. Hysteria was mainly conceptualized as today's somatization disorder. This view strongly influenced the revisions of classifications of mental disorders in North American psychiatry in the 1980s. The connections of this concept of hysteria to antisocial personality disorder and alcoholism have been investigated to unravel, among other things, possible genetic links between these conditions (Bohman, Cloninger, Von Knorring, \& Sigvardsson, 1984).

Reintroducing a broader concept covering both somatoform and psychological aspects of hysteria, Braun (1988) came up with the BASK model of dissociation and pointed out the disconnection between behavior (B), affect (A), sensation $(\mathrm{S})$, and knowledge $(\mathrm{K})$ that results from dissociation. Underlining the equal importance of dissociation's disintegrating effect on both psychological and somatic processes, Nijenhuis and colleagues (Nijenhuis, Spinhoven, Van Dyck, Van der Hart, \& Vanderlinden, 1996) introduced the term somatoform dissociation. These authors developed the Somatoform Dissociation Questionnaire (SDQ-20), a standardized instrument designed to evaluate somatoform aspects of dissociation. The development of this scale filled the gap after the development of such instruments as the Dissociative Experiences Scale (Bernstein \& Putnam, 1986) and the Dissociation Questionnaire (Vanderlinden, Van Dyck, Vandereycken, Vertommen, \& Verkes, 1993), which have been successfully applied to measure psychological dissociation. Nijenhuis and colleagues (Nijenhuis, Spinhoven, Van Dyck, Van der Hart, \& Vanderlinden, 1998a) demonstrated that somatoform dissociation is correlated with childhood sexual and physical abuse. They reawakened interest in and empirically investigated the relationship between animal defensive reactions and dissociative phenomena (Nijenhuis, Spinhoven, Vanderlinden, Van Dyck, \& Van der Hart, 1998; see also Nijenhuis, Vanderlinden, \& Spinhoven, 1998), pointing out the similarities between freezing, concomitant development of analgesia and anesthesia, and acute pain in threatened animals and severely traumatized humans.

The aim of this study was to assess the psychometric characteristics of the 
Turkish Version of the SDQ-20 and to evaluate whether dissociative disorders can be differentiated from other diagnostic groups through somatoform dissociation among Turkish patients. As somatization has been considered a culture-sensitive phenomenon (Tseng, 1975; Ulusahin, Basoglu, \& Paykel, 1993), we also compared our findings with those reported by Nijenhuis and colleagues (1996) and examined similarities and differences between the two study groups.

\section{METHODS}

\section{Participants}

The patients in the dissociative disorders group $(N=50)$ were cases of dissociative identity disorder (DID; $N=25$ ) or dissociative disorder not otherwise specified (DDNOS; $N=25$ ) who had been admitted to the Dissociative Disorders Program of the Psychiatric Department in the Istanbul Medical Faculty Hospital. The clinical diagnosis of dissociative disorder was confirmed using the Structured Clinical Interview for DSM-IV Dissociative Disorders (Steinberg, 1994) for all patients in this group.

Participants with schizophrenic disorder $(N=23)$, anxiety disorder $(N=$ $26)$, major depressive episode $(N=23)$, or bipolar mood disorder in remission $(N=22)$ came from various programs of the same department. All patients were diagnosed according to the DSM-IV criteria. Additionally, a non-clinical group of 175 participants were recruited from college students $(N=50)$, workers in the textile industry $(N=53)$, homemakers $(N=42)$, and bank employers $(N=30)$. Informed consent was obtained after the study was fully explained to all participants.

\section{Assessment Measures}

1. Somatoform Dissociation Questionnaire: The SDQ-20 is a 20-item selfreport instrument that evaluates the severity of somatoform dissociation. The SDQ-20 was developed by Nijenhuis and colleagues (1996). It has excellent internal consistency (Cronbach's alpha $=0.95)$. Mokken scale analysis showed that the 20 items were strongly scalable (Nijenhuis et al., 1996; Nijenhuis, Spinhoven, Van Dyck, Van der Hart, \& Vanderlinden, 1998b). The SDQ-20 total score was strongly correlated with DIS-Q $(r=0.76)$ and DES $(r=0.85)$ (Nijenhuis et al., 1996, 1999) and with reported trauma (Nijenhuis et al., 1998a). The short form of the scale, which includes five items of the 20-item version, is a screening instrument for DSM-IV dissociative disorders (Nijenhuis, Spinhoven, Van Dyck, Van der Hart, \& Vanderlinden, 1997). The SDQ-20 was translated into Turkish by the first author. 
2. Structured Clinical Interview for DSM-IV Dissociative Disorders: The SCID-D is a semi-structure interview developed by Steinberg (1994). It is a diagnostic instrument. The Turkish Version of the SCID-D has excellent interrater reliability and validity (Kundakci, Sar, Kiziltan, Yargic, \& Tutkun, 1998).

3. Dissociative Experiences Scale: The DES (Bernstein \& Putnam 1986; Carlson \& Putnam, 1993) is a 28-item self-report instrument. It has been demonstrated that the scale differentiates patients with a chronic dissociative disorder from those with other psychiatric disorders (Carlson et al., 1993). The Turkish version of the scale has a reliability and validity (Yargic, Tutkun, \& Sar, 1995; Sar et al., 1997) equal to its original form.

4. Dissociation Questionnaire: The DIS-Q is a 63 item self-report instrument (Vanderlinden et al., 1993). It evaluates the severity of psychological dissociation with possible scores ranging from 1 to 5. According to a study among Turkish patient groups, the DIS-Q differentiates patients with a chronic dissociative disorder from those with other psychiatric disorders (Sar et al., 1998). The reliability and validity of the Turkish version of the scale are equal to the psychometric characteristics of the original form (Sar et al., 1998).

5. Childhood Abuse and Neglect Questionnaire: The CANQ is a short self-report questionnaire that gathers information on details of childhood abuse and neglect. It was developed by Yargic, Tutkun, and Sar (1994) according to the definitions of childhood abuse and neglect by Walker, Bonner, and Kaufmann (1988).

\section{RESULTS}

\section{Characteristics of the Participants}

The demographic data concerning the participants are contained in Table 1. The mean age of the outpatients with dissociative disorder was 24.5 ( $S D=$ $4.8)$ with a range of 18 to 37 . Their mean education was $8.3(S D=3.8)$ years. Dissociative patients were younger than the patients with bipolar mood disorder, schizophrenic disorder, and the non-clinical group, $F(5,313)=6.23, p<$ 0.001 , on analysis of variance with post hoc Scheffé test. They also had received less education than the non-clinical group and patients with bipolar mood disorder, $F(5,313)=6.51, p<0.001$.

In the dissociative disorders group, $45(90 \%)$ patients reported at least one type of childhood abuse and/or neglect, 23 (46\%) reported childhood sexual abuse, 33 patients $(66 \%)$ reported physical abuse, and $33(66 \%)$ emotional abuse in childhood. Thirty-seven (74\%) patients mentioned neglect. 
TABLE 1. Sociodemographic Characteristics of the Participants

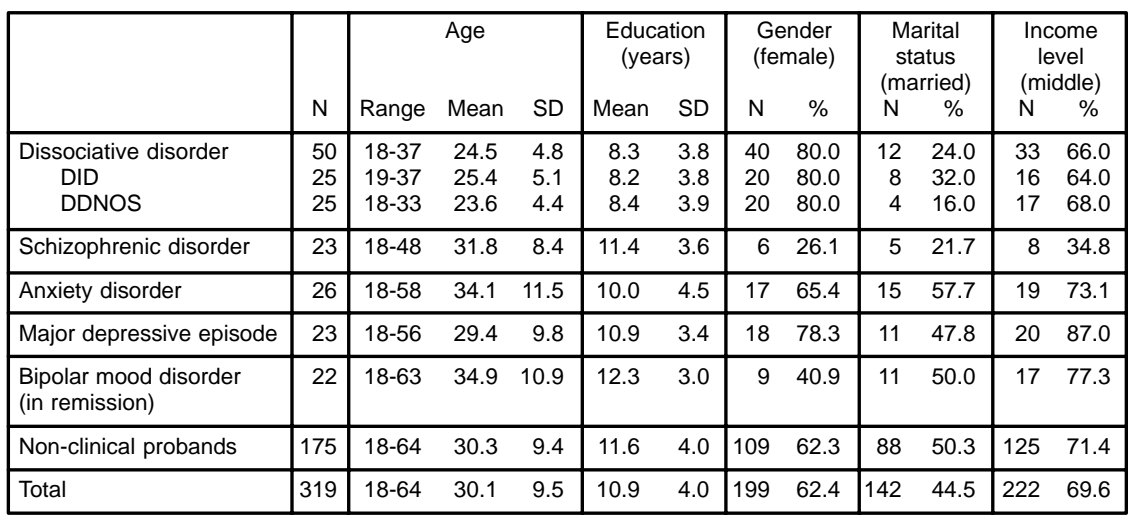

\section{Reliability Measures}

The first step was to determine if SDQ-20 scores could be accounted for by variables other than group membership as assessed among participants in a non-clinical population. There was a weak but significant correlation between SDQ-20 and age $(r=0.20, N=175, p<0.05)$. There was no significant difference between the scores of male $(M=27.0, S D=8.7)$ and female $(M=$ $27.6, S D=7.9)$ participants, $(t(173)=0.45, p>0.05)$. However, there were negative correlations (Pearson) between SDQ-20 total score and economic status $(r=\square$ 0.24, $N=175, p<0.005)$, and education $(r=\square 0.35, N=175$, $p<0.001)$.

For all participants $(N=319)$, the Pearson correlations were calculated between each item and item-corrected SDQ-20 scores to establish partial construct validity of the scale. These coefficients ranged between $r=0.46$ and $r=0.80$. All correlations reached a significance level of $p<0.001$ or better.

Test-retest reliability was calculated using Pearson correlations from the scale scores of 35 persons (including 9 dissociative cases) who completed the scale on two occasions separated by an average interval of 33.2 days $(S D=$ 14.0, range 21-76). The overall test-retest correlation was $r=0.95$ for the total score $(N=35, p<0.001)$. The test-retest correlations of 19 individual variables varied between 0.63-0.93 with a significance of at least $p<0.001$, one item (No. 9: "I dislike smells that I usually like") had a correlation of $r=$ $0.37(p<0.05)$. Thus, the SDQ-20 score is stable over an interval of approximately one month.

Cronbach's alpha coefficients were calculated for the sample as a whole 
$(N=319$, alpha $=0.94)$ and for each of the subsamples: dissociative disorders $($ alpha $=0.92)$; schizophrenic disorder $($ alpha $=0.89)$; anxiety disorder $($ alpha $=$ $0.82)$; major depressive episode $($ alpha $=0.85)$; bipolar mood disorder $($ alpha $=$ $0.77)$; non-clinical participants (alpha $=0.87$ ). A second measure of internal consistency, split-half reliability (Gutmann's split-half), was calculated for the sample as a whole $(r=0.92, N=319)$ and for each subgroup: dissociative disorders $(r=0.91)$; schizophrenic disorder $(r=0.80)$; anxiety disorder $(r=$ $0.79)$; major depressive episode $(r=0.83)$; bipolar mood disorder $(r=0.82)$; and non-clinical volunteers $(r=0.82)$. These values indicate that the SDQ-20 is an internally consistent measure across all test samples.

\section{Comparison of the Groups and Diagnostic Accuracy}

There were high correlations between the SDQ-20, the DIS-Q $(r=0.80, N=$ $236, p<0.001)$, and the DES $(r=0.76, N=173, p<0.001)$. The correlations between the SDQ-20 and the four DIS-Q factor scores (identity fragmentation factor $r=0.79$, loss of control $r=0.76$, amnesia $r=0.78$, and absorption $r=0.58)$ were also strong. These data support the convergent validity of the SDQ-20.

Patients with dissociative identity disorder had the highest score on the SDQ-20 $(M=58.7, S D=17.88$, range 26-90). The mean SDQ-20 scores in the remaining groups were between 22.7 and 27.4. A variance analysis was performed to compare SDQ-20 scores across these groups. They differed significantly $F(5,313)=53.81, p<0.001)$. Pairwise comparisons were then performed with a Scheffè test demonstrating significant differences between the dissociative disorder group and all other groups (Table 2). As seen in Figure 1, a cut-off point of 35 seems to be suitable in screening for cases of DSM-IV dissociative disorders.

TABLE 2. SDQ-20 Total Score in Various Diagnostic Groups

\begin{tabular}{|l|c|cc|c|c|c|}
\hline & N & Mean & SD & Range & Median & $\begin{array}{c}\text { Items } \\
\text { endorsed } \\
\text { (median) }\end{array}$ \\
\hline Dissociative disorder & 50 & 52.5 & 18.0 & $21-90$ & 49 & 15 \\
$\quad$ DID \\
DDNOS & 25 & 58.7 & 17.9 & $26-90$ & 58 & 17 \\
\hline Schizophrenic disorder & 23 & 27.1 & 9.5 & $20-61$ & 24 & 4 \\
\hline Anxiety disorder & 26 & 26.8 & 6.4 & $20-46$ & 25 & 5 \\
\hline Major depressive & 23 & 28.7 & 8.3 & $20-55$ & 28 & 4 \\
episode & 22 & 22.7 & 3.5 & $20-33$ & 22 & 2 \\
\hline Bipolar mood disorder & 175 & 27.4 & 8.2 & $20-73$ & 25 & 4 \\
\hline Non-clinical probands & & & & & & \\
\hline
\end{tabular}

$F(5,313)=53.81, p<0.001$ 
FIGURE 1. SDQ-20 Scores in Various Diagnostic Groups

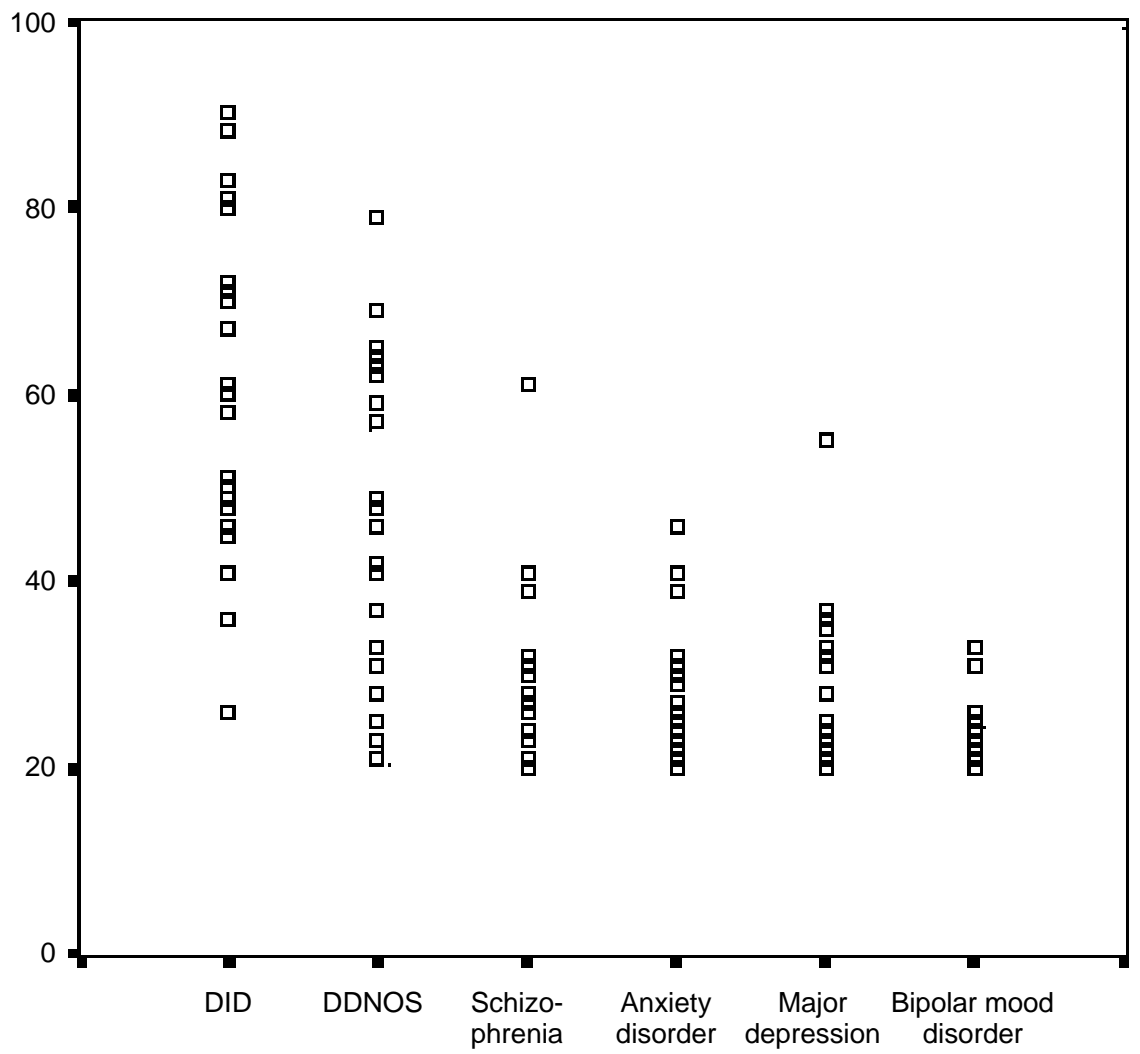

Specificity, sensitivity, and predictive values of the SDQ-20 are seen in Table 3. A cut-off point of 35 yielded a sensitivity of 0.84 , and a specificity of 0.87 for dissociative disorder diagnosis. Seven patients with DDNOS and one with DID remained below the cut-off point. In order to compare the discriminative power of somatoform dissociation with that of psychological dissociation, we analyzed the DES scores of 49 dissociative patients with those of the 71 patients with other psychiatric diagnoses. At a cut-off point of 25 and above, the sensitivity of the DES was 0.84 and the specificity 0.89 , revealing similar discriminating powers for both somatoform and psychological dissociation.

\section{Cross-Cultural Comparison}

As the patient groups in both studies have similar proportions of dissociative identity disorder and dissociative disorder not otherwise specified, these 
TABLE 3. Sensitivity and Specificity of the SDQ-20 at Various Cutoff Scores Discriminating Between 50 DSM-IV Dissociative Disorder Patients and 94 Psychiatric Patients with Other Disorders

\begin{tabular}{|c|c|c|c|c|cc|cc|}
\hline Cutoff score & Sensitivity & Specificity & $\begin{array}{c}\text { Positive } \\
\text { predictive } \\
\text { value }\end{array}$ & $\begin{array}{c}\text { Negative } \\
\text { predictive } \\
\text { value }\end{array}$ & \multicolumn{2}{|c|}{$\begin{array}{c}\text { Predictive value } \\
\text { estimated at } \\
\text { prevalence 10\% } \\
\text { Positive }\end{array}$} & Negative & Likelihood rate \\
& & & & & & \\
\hline 40 & 0.74 & 0.94 & 0.88 & 0.87 & 0.58 & 0.97 & 12.3 & 0.28 \\
\hline 35 & 0.84 & 0.87 & 0.78 & 0.91 & 0.45 & 0.98 & 6.5 & 0.18 \\
\hline 30 & 0.90 & 0.75 & 0.66 & 0.93 & 0.29 & 0.99 & 3.6 & 0.13 \\
\hline
\end{tabular}

similarities and differences cannot be considered artifacts. There were no significant differences in SDQ-20 items between Turkish and Dutch (Nijenhuis et al., 1996) dissociative patients including the total score of the scale (Table 4). Turkish patients had higher scores on items considering tastes, smells, and pseudoseizures, whereas Dutch patients more frequently reported difficulty in swallowing.

A logistic regression analysis revealed that three items of the SDQ-20 predicted membership to dissociative disorders group among Turkish patients. These were, being paralyzed for a while, hearing sounds from nearby as if they come from far away, and difficulty swallowing. It is noteworthy that none of these items are included in the short version (SDQ-5) derived from Dutch dissociative patients with the same methodology (i.e., having pain while urinating, feeling that a part of the body has disappeared, being unable to speak, insensitivity to pain, and seeing things around differently than normal). With cutoff score of 8 , the sensitivity and specificity of the SDQ-5 were 0.90 and 0.75 , respectively (Table 5). The diagnostic accuracy of SDQ-5 is rather limited among Turkish patients compared to the high sensitivity (0.94) and specificity (0.98) rates obtained in Dutch patients (Nijenhuis et al., 1997).

\section{DISCUSSION}

The excellent internal consistency and high test-retest correlation suggest that the Turkish Version of the SDQ-20 is a reliable instrument. Gender does not affect SDQ-20 scores. However, Turkish volunteers who were older, less well educated and had less income had higher scores. Somatization has long been reported as more frequently observed in individuals from lower socioeconomic levels (Crandell \& Dohrenwend, 1967). The negative correlation between the SDQ-20 scores and income and education seem to reflect this 
TABLE 4. Somatoform Dissociative Symptoms of Patients with Dissociative Disorders in Turkey and in the Netherlands (Nijenhuis et al., 1996)

\begin{tabular}{|c|c|c|c|c|c|c|}
\hline Items & \multicolumn{2}{|c|}{$\begin{array}{l}\text { Present } \\
\text { study } \\
(\mathrm{N}=50)\end{array}$} & \multicolumn{2}{|c|}{$\begin{array}{l}\text { Nijenhuis } \\
\text { et al. } \\
(\mathrm{N}=50)\end{array}$} & $t(d f=98)$ & $\mathrm{p}$ \\
\hline $\begin{array}{l}\text { I hear sounds from nearby as if they come from } \\
\text { far away. }\end{array}$ & 3.1 & 1.7 & 2.7 & 1.3 & 1.33 & n.s. \\
\hline My body, or a part of it, feels numb. & 3.1 & 1.4 & 3.1 & 1.2 & 0.00 & n.s. \\
\hline $\begin{array}{l}\text { I cannot speak (or merely with great effort) or } \\
\text { I can only whisper. }\end{array}$ & 3.0 & 1.3 & 2.6 & 1.4 & 1.48 & n.s. \\
\hline $\begin{array}{l}\text { I do not have a cold but yet am able to smell much } \\
\text { better or worse than I usually do. }\end{array}$ & 3.0 & 1.4 & 1.9 & 1.3 & 4.07 & $<0.001$ \\
\hline $\begin{array}{l}\text { I cannot sleep for nights on end, but remain very } \\
\text { active during daytime. }\end{array}$ & 2.9 & 1.5 & 2.9 & 1.5 & 0.0 & n.s. \\
\hline My body, or a part of it, is insensitive to pain. & 2.8 & 1.5 & 2.9 & 1.5 & 0.33 & n.s. \\
\hline I cannot hear for a while (as if I were deaf). & 2.8 & 1.4 & 2.5 & 1.3 & 1.07 & n.s. \\
\hline $\begin{array}{l}\text { I feel pain in my genitals (apart from sexual } \\
\text { intercourse). }\end{array}$ & 2.7 & 1.5 & 2.6 & 1.4 & 0.34 & n.s. \\
\hline I grow stiff for a while. & 2.7 & 1.4 & 2.7 & 1.4 & 0.0 & n.s. \\
\hline I dislike smells that I usually like. & 2.7 & 1.5 & 2.0 & 1.2 & 2.59 & $<0.05$ \\
\hline $\begin{array}{l}\text { I dislike tastes that I usually like (women: apart } \\
\text { from pregnancy or monthly periods). }\end{array}$ & 2.7 & 1.4 & 2.1 & 1.2 & 2.31 & $<0.05$ \\
\hline $\begin{array}{l}\text { I see things around me differently than usual } \\
\text { (for example, as if looking through a tunnel, or } \\
\text { seeing merely a part of an object). }\end{array}$ & 2.6 & 1.4 & 2.8 & 1.4 & 0.71 & n.s. \\
\hline People and things look bigger than they actually are. & 2.6 & 1.5 & 2.4 & 1.5 & 0.67 & n.s. \\
\hline I have an attack that resembles an epileptic fit. & 2.6 & 1.6 & 1.5 & 1.1 & 4.07 & $<0.001$ \\
\hline I cannot swallow, or only with great effort. & 2.5 & 1.4 & 3.1 & 1.5 & 2.07 & $<0.05$ \\
\hline It is as if my body, or a part of it, has disappeared. & 2.5 & 1.2 & 2.5 & 1.5 & 0.00 & n.s. \\
\hline I am paralyzed for a while. & 2.2 & 1.3 & 1.9 & 1.3 & 1.15 & n.s. \\
\hline I cannot see for a while (as if I were blind). & 2.2 & 1.2 & 1.9 & 1.3 & 1.20 & n.s. \\
\hline I have trouble urinating. & 2.1 & 1.2 & 1.9 & 1.2 & 0.83 & n.s. \\
\hline I have pain while urinating. & 2.1 & 1.2 & 1.9 & 1.2 & 0.83 & n.s. \\
\hline Total score & 52.5 & 18.0 & 48.1 & 15.2 & 1.32 & n.s. \\
\hline
\end{tabular}

general trend. The positive correlation between somatoform dissociation and age, however, provides a contrast against psychological dissociation. Psychological dissociation was shown to be higher among younger participants in a large representative sample derived from Sivas-City in Turkey (Akyuz, Dogan, Sar, Yargic, \& Tutkun, 1999).

Convergent validity was shown by the high correlations between the SDQ-20, the DES, and the DIS-Q. The SDQ-20 scores differentiated the 
TABLE 5. Sensitivity and Specificity of the SDQ-5 at Various Cutoff Scores Discriminating Between 50 DSM-IV Dissociative Disorder Patients and 94 Psychiatric Patients with Other Disorders

\begin{tabular}{|c|c|c|c|c|c|c|c|c|}
\hline $\begin{array}{c}\text { Cutoff score } \\
>=\end{array}$ & Sensitivity & Specificity & $\begin{array}{l}\text { Positive } \\
\text { predictive } \\
\text { value }\end{array}$ & $\begin{array}{l}\text { Negative } \\
\text { predictive } \\
\text { value }\end{array}$ & $\begin{array}{r}\text { Predic } \\
\text { estim } \\
\text { prevale } \\
\text { Positive }\end{array}$ & $\begin{array}{l}\text { value } \\
\text { d at } \\
\text { 10\% } \\
\text { Jegative }\end{array}$ & $\begin{array}{r}\text { Likelir } \\
\text { Positive }\end{array}$ & $\begin{array}{l}\text { od rate } \\
\text { Negative }\end{array}$ \\
\hline 9 & 0.80 & 0.84 & 0.71 & 0.89 & 0.33 & 0.97 & 5.0 & 0.24 \\
\hline 8 & 0.90 & 0.75 & 0.66 & 0.93 & 0.29 & 0.99 & 3.6 & 0.13 \\
\hline 7 & 0.92 & 0.61 & 0.55 & 0.93 & 0.21 & 0.99 & 2.4 & 0.13 \\
\hline
\end{tabular}

dissociative disorders group from other diagnostic groups in the current study, as has been previously demonstrated for Dutch patients (Nijenhuis et al., 1996, 1998b, 1999). The sensitivity (0.84) and specificity $(0.87)$ of the SDQ-20 for dissociative disorder was slightly lower among Turkish patients than those reported by Nijenhuis and colleagues (1996), 0.88 and 0.94, respectively. The discriminating power of the SDQ-20 was, however, not lower than that of the DES among Turkish patients in this study. Taken a score of 25 or above as cutoff point, the sensitivity and specificity of the DES were 0.84 and 0.89 , respectively. A considerable proportion $(28.0 \%)$ of the Turkish patients with DDNOS had low SDQ-20 scores, that is, scores below the cut-off point. This rate was $23.8 \%$ with SDQ-5 for DDNOS and only $4.3 \%$ for DID among Dutch patients (Nijenhuis et al., 1999).

The scores obtained in most items of the SDQ-20 in this study were very similar to those of the Dutch patients (Nijenhuis et al., 1996). Turkish dissociative patients had higher scores for some items, including pseudoseizures. This finding is not at odds with previous reports, as pseudoseizure is one of the most frequently seen somatoform symptoms in Turkey (Sar \& Sar, 1990). It is usually a presentation form of a more complex psychiatric condition including chronic dissociative disorders (Bowman \& Markand, 1996). There is also an association between pseudoseizures and sexual abuse (Bowman \& Markand, 1996; Litwin \& Cardeña, 2000, this issue). Nijenhuis and colleagues (1998a) reported that childhood sexual and physical abuse were correlated with somatoform dissociation. In the present study, $90 \%$ of the dissociative disorder group reported at least one type of childhood abuse and/or neglect.

The logistic regression analysis revealed three symptoms as the features that best distinguish the Turkish dissociative group from other psychiatric patients: i.e., being paralyzed for a while, hearing sounds from nearby as if they come from far away, and difficulty swallowing ("globus hystericus"). When combined, this pattern describes a crisis situation ("fainting fit") close 
to pseudoseizure. Surprisingly, none of the items from the Dutch SDQ-5 were among these symptoms. Having low specificity in Turkish study group, the cross-cultural validity of the short form of the scale is not supported by our data. Despite this discrepancy, both the SDQ-5 and the symptom pattern derived from Turkish patients resemble different types of the same freezing response (Nijenhuis et al., 1998). For Turkish patients, motor inhibition is the predominant characteristic, whereas the Dutch SDQ-5 consists of items concerning perception, including pain and analgesia. We believe that the differences in severity and quality of childhood trauma histories between the two study groups play a role in this discrepancy. Among Nijenhuis et al.'s (1998a) dissociative patients, $82 \%$ reported childhood sexual abuse whereas it was only $46 \%$ in this study. Childhood abuse histories reported by Turkish dissociative patients seldom have brutal components (Sar, Tutkun, Yargic, \& Kundakci, 1999; see also Sar, Tutkun, Alyanak, Bakim, \& Baral, 2000).

We conclude that somatoform dissociation is as powerful as psychological dissociation in discriminating patients with dissociative disorders from patients with other psychiatric disorders. The SDQ-20, developed using Dutch and Flemish patients, has excellent psychometric properties among Turkish participants. Further studies are needed to evaluate probable cultural differences in various symptoms of somatoform dissociation and in factors associated with them.

RECEIVED: 5/07/00

REVISED: $7 / 07 / 00$ and 8/06/00

ACCEPTED: 8/23/00

\section{REFERENCES}

Akyuz, G., Dogan, O., Sar, V., Yargic, L.I., \& Tutkun, H. (1999). Frequency of dissociative identity disorder in the general population in Turkey. Comprehensive Psychiatry, 40, 151-159.

American Psychiatric Association (1968). Diagnostic and statistical manual of mental disorders, second edition. Washington, DC: American Psychiatric Association.

American Psychiatric Association (1980). Diagnostic and statistical manual of mental disorders, third edition. Washington, DC: American Psychiatric Association.

American Psychiatric Association (1994). Diagnostic and statistical manual of mental disorders, fourth edition. Washington, DC: American Psychiatric Association.

Bernstein, E.M., \& Putnam, F.W. (1986). Development, reliability and validity of a dissociation scale. Journal of Nervous and Mental Disease, 174, 727-735.

Bohman, M., Cloninger, C.R., Von Knorring, A.L., \& Sigvardsson, S. (1984). An adoption study of somatoform disorders. Archives of General Psychiatry, 41, 872-878.

Bowman, E.S. (1993). Etiology and clinical course of pseudoseizures: Relationship to trauma, depression, and dissociation. Psychosomatics, 34, 333-342. 
Bowman, E.S., \& Markand, O.N. (1996) Psychodynamics and psychiatric diagnoses of pseudoseizure subjects. American Journal of Psychiatry, 153, 57-63.

Braun, B.G. (1988). The BASK (behavior, affect, sensation, knowledge) model of dissociation. Dissociation, 1, 4-23.

Carlson, E.B., \& Putnam, F.W. (1993). An update on Dissociative Experiences Scale. Dissociation, 6, 16-27.

Carlson, E.B., Putnam, F.W., Ross, C.A., Torem, M., Coons, P., Dill, D.L., Loewenstein, R.J., \& Braun, B.G. (1993). Validity of the Dissociative Experiences Scale in screening for multiple personality disorder: A multicenter study. American Journal of Psychiatry, 150, 1030-1036.

Crandell, D.L., \& Dohrenwend, B.P. (1967). Some relations among psychiatric symptoms, organic illness, and social class. American Journal of Psychiatry, 123, 1527-1538.

Freud, S. (1895/1974). Studien über Hysterie. München: Fischer Taschenbuch Verlag.

Guze, S.B. (1975). The validity and significance of the clinical diagnosis of hysteria (Briquet's syndrome). American Journal of Psychiatry, 132, 138-141.

Kretschmer, E. (1944). Hysterie, Reflex, Instinkt, dritte Auflage. Leipzig: Georg Thieme Verlag.

Kretschmer, E. (1975). Medizinische Psychologie, 14. ergaenzte und bearbeitete Auflage. W. Kretschmer (Ed.), Stuttgart: Georg Thieme Verlag.

Kundakci, T., Sar, V., Kiziltan, E., Yargic, L.I., \& Tutkun, H. (1998). The reliability and validity of the Turkish version of the SCID-D. Paper presented at the 15 th Fall Meeting of the International Society for the Study of Dissociation, Seattle.

Nijenhuis, E.R.S., Spinhoven, P., Van Dyck, R., Van der Hart, O., \& Vanderlinden, J. (1996). The development and psychometric characteristics of the Somatoform Dissociation Questionnaire (SDQ-20). Journal of Nervous and Mental Disease, 184, 688-694.

Nijenhuis, E.R.S., Spinhoven, P., Van Dyck, R., Van der Hart, O., \& Vanderlinden, J. (1997). The development of the somatoform dissociation questionnaire (SDQ-5) as a screening instrument for dissociative disorders. Acta Psychiatrica Scandinavica, 96, 311-318.

Nijenhuis, E.R.S., Spinhoven, P., Vanderlinden, J., Van Dyck, R., \& Van der Hart, O. (1998). Somatoform dissociative symptoms as related to animal defensive reactions to predatory threat and injury. Journal of Abnormal Psychology, 107, 63-73.

Nijenhuis, E.R.S., Spinhoven, P., Van Dyck, R., Van der Hart, O., \& Vanderlinden, J. (1998a). Degree of somatoform and psychological dissociation in dissociative disorder is correlated with reported trauma. Journal of Traumatic Stress, 11, 711-730.

Nijenhuis, E.R.S., Spinhoven, P., Van Dyck, R., Van der Hart, O., \& Vanderlinden, J. (1998b). Psychometric characteristics of the Somatoform Dissociation Questionnaire: A replication study. Psychotherapy and Psychosomatics, 67, 17-23.

Nijenhuis, E.R.S., Vanderlinden, J., \& Spinhoven, P. (1998). Animal defensive reactions as a model for trauma-induced dissociative reactions. Journal of Traumatic Stress, 11, 243-260.

Nijenhuis, E.R.S., \& Van der Hart, O. (1999). Somatoform dissociative phenomena: A Janetian perspective. In J.M. Goodwin and R. Attias (Eds.), Splintered reflections: Images of the body in trauma (pp. 89-127). New York: Basic Books. 
Nijenhuis, E.R.S., Van Dyck, R., Spinhoven, P., Van der Hart, O., Chatrou, M., Vanderlinden, J., \& Moene, F. (1999). Somatoform dissociation discriminates among diagnostic categories over and above general psychopathology. Australian and New Zealand Journal of Psychiatry, 33, 511-520.

Sar, I., \& Sar, V. (1990). Konversiyon bozuklugunda belirti dagilimi. [Symptom patterns in conversion disorder.] Uludag Üniversitesi Tip Fakultesi Dergisi, 17, 67-74.

Sar, V., Kiziltan, E., Kundakci, T., Bakim, B., Yargic, L.I., \& Bozkurt, O. (1998). The reliability and validity of the Turkish version of the Dissociation Questionnaire $(D I S-Q)$. Paper presented at the 15th Fall Meeting of the International Society for the Study of Dissociation, Seattle.

Sar, V., Kundakci, T., Kiziltan, E., Bakim, B., Yargic, L.I., \& Tutkun, H. (1997). Dissosiyatif yasantilar ölceginin (DES-II) Türkce versiyonunun gecerlik ve güvenilirligi. [Reliability and validity of the Turkish Version of the Dissociative Experiences Scale (DES-II).] in Turkish Psychiatric Society (Ed.), Proceedings of the 33th National Congress of Psychiatry (pp. 55-64). Antalya: Turkish Psychiatric Society.

Sar, V., Tutkun, H., Alyanak, B., Bakim, B., \& Baral, I. (2000). Frequency of dissociative disorders among psychiatric outpatients in Turkey. Comprehensive Psychiatry, 41, 216-222.

Sar, V., Tutkun, H., Yargic, L.I., \& Kundakci, T. (1999). Kronik karmasyk dissosiyatif bozukluklarda çocukluk çagy cinsel travma öyküsünün dogrulanma düzeyi. [Confirmation of reported childhood sexual abuse in chronic complex dissociative disorder]. Ege Psikiyatri Sürekli Yayinlari, 4, 95-108.

Saxe, G., Chinman, G., Berkowitz, R., Hall, K.H., Lieberg, G., Schwartz, J., \& Van der Kolk, B.A. (1994). Somatization in patients with dissociative disorders. American Journal of Psychiatry, 151, 1329-1334.

Steinberg, M. (1994). Structured Clinical Interview for DSM-IV Dissociative Disorders-Revised (SCID-D-R). Washington, DC: American Psychiatric Press (Translated and adapted into Turkish by Sar, V., Tutkun, H., Yargic, L.I., Kundakci, T., \& Kiziltan, E., 1996).

Tseng, W.-S. (1975). The nature of somatic complaints among psychiatric patients: The Chinese case. Comprehensive Psychiatry, 16, 237-245.

Ulusahin, A., Basoglu, M., \& Paykel, E.S. (1993). A cross-cultural comparative study of depressive symptoms in British and Turkish clinical samples. Social Psychiatry and Psychiatric Epidemiology, 29, 31-39.

Vanderlinden, J., Van Dyck, R., Vandereycken, W., Vertommen, H. \& Verkes, R.J. (1993). The Dissociation Questionnaire: Development and characteristics of a new self-reporting questionnaire. Clinical Psychology and Psychotherapy, 1, 21-27.

Walker, C.E., Bonner, B.L., \& Kaufmann, K.L. (1988). The physically and sexually abused child: Evaluation and treatment. New York: Pergamon Press.

World Health Organization (1992). International classification of diseases, edition 10. Geneva: World Health Organization.

Yargic, L.I., Tutkun, H., \& Sar, V. (1994). Cocukluk cagi travmalari ve eriskinde dissosiyatif belirtiler [Childhood traumas and dissociative experiences in adulthood]. Psikiyatri, Psikoloji, Psikofarmakoloji Dergisi, 2, 338-347.

Yargic, L.I., Tutkun, H., \& Sar, V. (1995). The reliability and validity of the Turkish version of the Dissociative Experiences Scale. Dissociation, 8, 10-13. 